Burak GÖRAL / Sinemanın Yapay Zekâya Bakışı

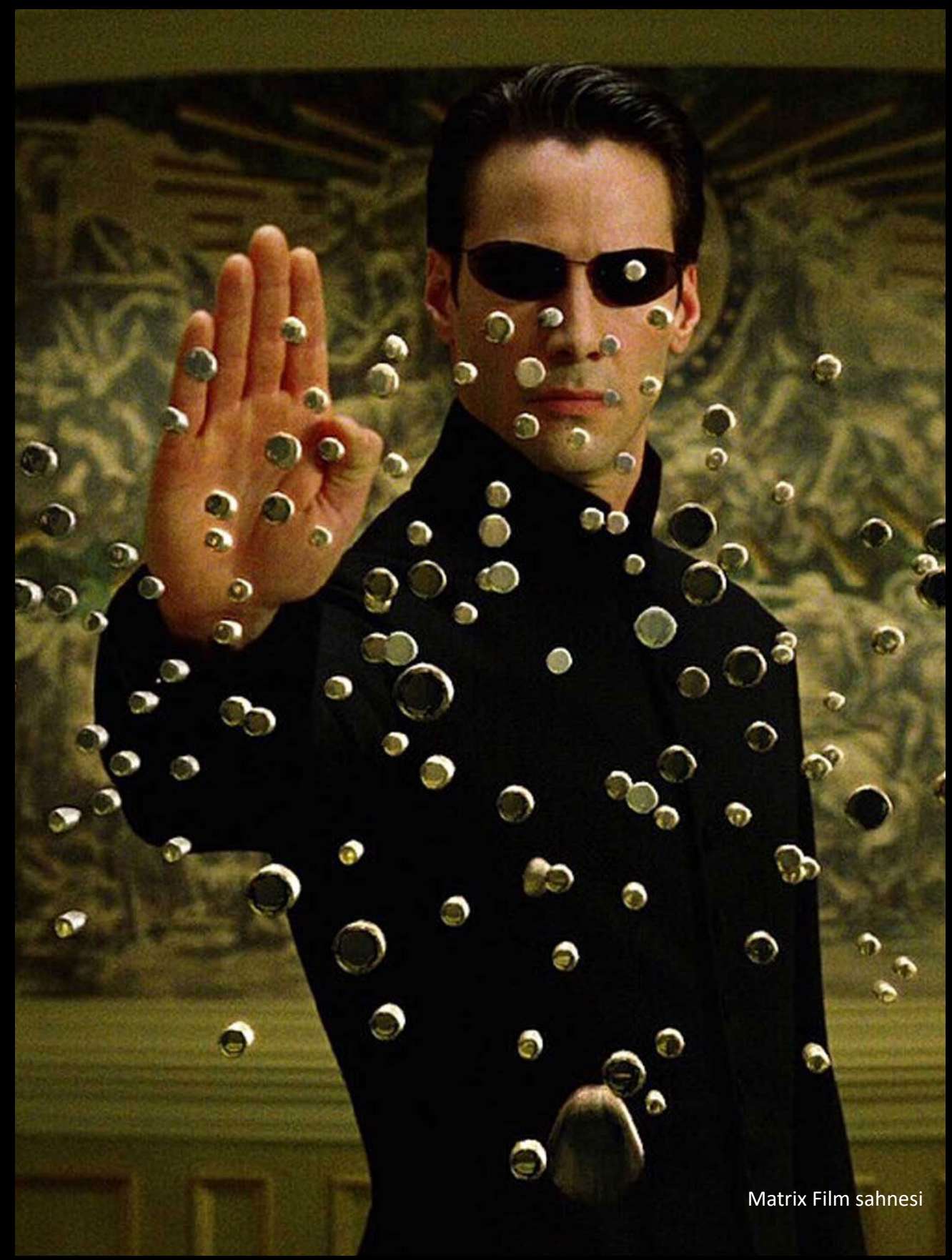




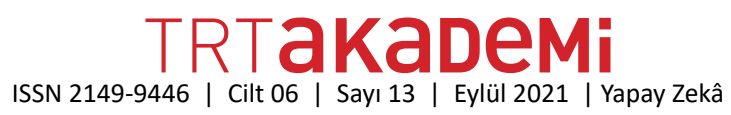

\section{Sinemanın Yapay Zekâya Bakışı}

\section{Burak GÖRAL*}

Filmlerin insanların düşünce dünyalarına katkı sunması ne kadar harika bir şeydir! Özellikle de bilim kurgu sinemasının düşünen ve düşündüren filmlerinin. Bilim kurgu edebiyatının birçok başyapıt gibi sinemanın bu türüne ait pek çok iyi film de insanlığa uyarı niteliği taşır. İnsanoğlunun ve dünyanın geleceğine dair fikirler öne sürer, öngörülerde bulunurlar. Üstelik bugünün insanının da eleştirisini yaparlar.

Bu açıdan bakınca, yapay zekâyı anlatan ya da içinde yapay zekâ teknolojisini barındıran her hikâye, bir insanlık eleştirisi ve araştırmasıdır aynı zamanda. İster bunu aksiyon janrı içinde bir filmle isterse korku filmi kalıpları içinde yapsın. Bilimsel gelişmeler ya da öngörülerin insanlar üzerindeki etkileri sinemanın her türden filmi için her zaman ilgi çekici olmuştur. Hele ki "yapay zekâ" gibi içinde ikilemleri, paradoksları bolca barındıran bir mesele, sinemanın en sevdiği çatışma türlerinden birini sunar sanatçılara.

Çünkü insanın eksikliğini bildiği, yetişemediği, eremediği ama mutlaka ulaşmak istediği özlemlerinden ortaya çıkar "yapay zekâ". Bu yolda ulaşılan her durak ilgi çekici birçok farklı hikâyeye davetiye çıkarır. Çok da egosal bir meseledir ve egosal her yaratım gibi aşılması pek kolay olmayan bazı sorunları da beraberinde getirir. Kendi düşünce sistemi olan bir yapay zekânın geliştikçe kendi yaratanını merak etmesi, insan denen kompleks organizmayı hem erdemleriyle hem de zaaflarıyla keşfetme macerası bütün hayalperestleri heyecanlandırır elbette. Pek çok hikâye ve filmde yapay zekânın giderek bu zaafları kullanabileceği bir duruma kendisini yükseltmesi, yükselttikçe de ironik bir şekilde "insanlaşıp" yine insana düşman olması işlenir.

* Film Eleştirmeni DOI: 10.37679/trta.1002528 
Peki, insanların düşünüp hissedebilen ve kendisini geliştirebilen makineler yapma isteği hangi içgüdüsel nedene bağlanabilir acaba? Büyük bir ego tatmini mi? Bazı insanlarda "Tanrı kompleksi" adıyla kendisini gösteren bir sendromun sonucu mu? İnsan hayatlarının riske girdiği alan ve durumlarda kullanılacak "insansı" makineler yaratarak insanları o risklerden koruma içgüdüsü mü?

Yapay zekâyı işleyen filmler genelde bunların hepsini birden düşünen, irdeleyen ve sorgulayan filmler oldular. Bu filmlerin ortak paydası; insanları, ne kadar ustalıkla üretilirse üretilsin, makinelerden ayıran en temel özellik olan "ruh" ve "vicdan"ın, insan eliyle ve aklıyla üretilebilen mekanik şeyler olmadıklarını anlatmaları. İnsan denen mucizenin yine bir insan tarafindan üretilemeyecek bir varlık olması. Üretilen teknoloji ürünü, insanoğlunun iyi özelliklerine doğru mu yoksa zaaflarına doğru mu gelişeceği önemli bir vurgudur. Diğer yandan da "insan kalbinin haritası" belki tıbben elimizde bulunuyordur ama onun manevi yapısını çözebilip bir makinenin bedenine eklemleyebilmek hâlâ pek de mümkün değildir!

\section{Yapay Zekânın Yaşam Hakkı}

Bilim kurgu edebiyatının üstat yazarlarından Philip K. Dick, eserlerinin çoğunda insanı insan yapan şeyin ne olduğunu merak eder ve araştırır. Okuyucularının da bunu düşünmesini sağlar. Sinemada mükemmel bir karşılığını bulmuş olan romanı “Do Androids Dream of Electric Sheep?"deki gibi. Yazarın bu kısa romanı Ridley Scott'ın yönettiği bir bilim kurgu başyapıtının çıkış noktasını oluşturur. 1982 yapımı Blade Runner, insanların kontrolünden çıkmış, yapay zekâlı insan benzeri androidlerin (replika) peşine düşmüş bir ödül avcısı olan Deckard'ın hikâyesini anlatır. Bu androidler de insanlar gibi "yaşam hakları" olduğunu savunan ve bunun için mücadele eden asilerdir. Deckard meselenin bu yönüyle hiç ilgilenmemiştir o zamana dek; o sadece işine bakmıştır ama dört kaçak replikayı kovalarken yaşadıkları onu büyük ikilemlere sürükleyecektir. "Bizi insan yapan şey nedir?” sorusu yakıcı bir şekilde tam ortasında durur filmin. Et ve kemikten oluşmak mı? Yoksa taşıdığın bilinç, vicdan, saygı ve sevgi mi? Scott’ın filmi film-noir çağrışımlı usta işi bir tekno-gerilim değildir sadece. Insanların farklı olanlara, azınlıklara yaptığı ayrıştırma politikasını da işleyen eleştirel bir yapıya da sahiptir. Scott'ın yapımcı stüdyoya karşı direttiği kendi kurgusunda Deckard ile replikalar arasındaki sınır iyice muğlaklaşır. Ana karakterinin aslında yaşam hakkı arayan bu azınlığın içinde olma ihtimalini de seyircinin aklına küçük bir soru işareti olarak ekler.

Yapay zekâyı geliştiren insanlar, makinenin gelişiminin bir sınırı olması gerektiğini düşünür ve bunu uygulamaya çalışırlar. Hem isyankâr olmasın hem de zekâsını insanlığa fayda sağlayacağı şekilde kullansın diye. Diğer yandan yakıcı bir şekilde, 
yapay zekânın oluşumuyla çelişen bir durumdur bu. Yapay zekâlı robotlar ya da bilgisayarlar insan geleceğine ve yaşamına tehdit oluşturmamalıdırlar elbette. Ancak yapay zekâ da her organizma gibi yaşamak için elindeki tüm özellikleri seferber etme eğiliminde olacaktır ve zekâsı geliştikçe içgüdüsel olarak takip edeceği yol, maalesef gücü eline geçiren insanınki gibi olmaktadır her seferinde! Hatta "insan"ı taklit ederek bazen sınırları da kötücül yöntemlerle zorlayabilmektedir. Yani yapay zekâyla uğraşmak böylesi bir paradoksu da yanında getirmektedir. Bilim kurgu edebiyatı ve sineması da bu paradoksu kurcalamayı her zaman çok sevmiştir.

Bilim kurgu edebiyatının temel yazarlarından biri sayılan Isaac Asimov'un 9 robot hikâyesini toplayan önemli eseri "Ben, Robot"taki bütün hikâyeler yazarın kurguladığı "3 Robot Yasası"nı içerir. Bu öyküler birbirlerinden bağımsız olsalar da robot psikoloğu olan bir karakterle birbirlerine bağlanırlar. Büyük oranda, kitaptaki dokuzuncu öykü olan “Önlenebilir Çatışma”dan uyarlanan 2004 yapımı Hollywood filmi Ben, Robot da (I, Robot) eserde belirtilen bu üç maddeden oluşan kanunla açılır:

Kanun 1 - Bir robot, bir insana zarar veremez veya zarar görmesine izin vermez.

Kanun 2 - Bir robot, birinci kanunu ihlal eden emirlerin haricinde insanların verdiği emirlere uymak zorundadır.

Kanun 3 - Bir robot, kendi varlığını korumak zorundadır ancak bu koruma birinci ve ikinci kanunu ihlal etmemelidir.

Bu kanunların esaslarına göre üretilmiş robotları yöneten Viki adlı yapay zekâ, artık bütün insanlığı korumanın sadece dünya yönetimini ele geçirmekle mümkün ve de mantıklı olacağını düşünmeye başlamıştır. "Üç kanun”u kendi eriştiği bilinçle yenilemiş, "update" etmiştir. Viki mucitleri olan ve baba olarak andıkları Profesör Arthur Lanning'in deyimiyle evrim geçirmiş ve iradesi dâhilinde şöyle bir fikir geliştirmiştir: "Ülkeleriniz savaşıyor, dünyayı kirletiyorsunuz ve gittikçe çeşitlenen yollarla bir öz yıkım gerçekleştiriyorsunuz. Kendi hayatınız size emanet edilmemeli. Sizi kendinizden korumamız gerek!"

Ben Robot filmi, ele aldığı paradoksun felsefesini çok kabaca çizen ve robot teknolojisine önyargılı bakan bir dedektifin Profesör Lanning'in şüpheli görünen intiharını soruşturması sırasında yaşadığı pahalı, bol efektli aksiyon sahneleriyle bir aksiyon filmidir. İnsan iradesine sahip olmadıkları için onlara güvenmeyen ve robot teknolojisine sayg duymayan dedektif karakterini Will Smith'in oynaması da pek anlamlı bir seçim gibi görünüyor diğer yandan. Çünkü "will” kelimesinin ingilizce karşılığı da "irade"dir. İnsanı makineden ayıran özelliklerinden biri sa- 
dece akıl ve mantığının değil kalbinin de belirleyici olduğu "irade"sidir. Filmdeki dedektifin akıllı robotlara karşı düşmanlığının sebebi, bir robotun sağ kalma ihtimalini düşük olarak hesapladığı için küçük bir çocuk yerine sağ kalma ihtimali daha yüksek olan bir yetişkini kurtarmayı seçmesidir. Onu harekete geçiren iradeyi kalbiyle değil hesapla oluşturması yani.

2014 yapımı Evrim (Transcendence) filminin başkarakterinin ismi de ironik bir şekilde, güç kazandıkça iradesini sadece kendi menfaatleri yönünde kullanacak olan Will'dir. Yapay zekâ uzmanı bir profesör olan Will'in karısı Evelyn, onu önemli bir panelde takdim ederken Albert Einstein'dan bir alıntı yapar: "Eğer insan ırkını kurtaracak ve refah seviyesini yükseltecekse yeni bir düşünme sistemi kesinlikle gereklidir." Bu cümle bilim insanları olan karı kocanın mottosudur. Zeki makineler, gezegeni iyileştirmek, yeni tedaviler bulmak ve insanları bazı külfetlerden, sorunlarından kurtarmak için yapılır. Ancak kimilerine göre de insana dokunaklı gelmesi için tasarlanmış bir satış cümlesidir sadece bu. Onlar bu amacı daha en başından itibaren samimi bulmuyorlardır. Film, yapay zekâ karşıtlarını bombalı eylemler yapan bir grup olarak kodlar. Bu konuda çalışmalar yapan bir sürü insanı öldürmekten çekinmeyen bu grup, Profesör Will'i de yeni bir tanrı yaratmaya yeltenmekle suçlar. Panel çıkışında onu zehirli bir kurşunla yaralarlar. Evelyn, kocasının gözlerinin önünde eriyerek ölüyor olmasına dayanamaz. Daha önce yaptıkları bir deneyden yola çıkarak en yakın arkadaşları Max'le birlikte Will'in beyninin dijital kopyasını çıkarırlar ve bu dijital kopya Will'in ölmeden önce üzerinde çalıştığı yapay zekâ ile birleştirilir. Will'in bu dijital hâli en başta Evelyn'e çok iyi gelir. Hâlâ onunla konuşabiliyordur en azından. Ancak Will daha fazla gelişmek için internette de çevrim içi olmak ister ve bu gerçekleşince de giderek kontrolden çıkar. Will'in yüzü ve beynine sahip olan "yapay zekâ" dünyanın toprağına ve suyuna karışacak kadar güçlenir giderek. Hatta Hz. İsa gibi hastalıkları iyileştirmeye bile başlar!

Korku-fantastik edebiyatının ünlü eserleri Frankenstein ve Dracula romanlarıyla flört eden bu hikâyede giderek çığırından çıkılıp hayatın doğal akışına çomak sokulmaktadır. Evelyn, büyük tutkuyla sevdiği insanı kaybetmek istemediği için bir felakete kapı aralamıştır.

Evrim, aslında bu konu hakkında güzel bir tartışma açacakmış gibi başlıyor ilk yarım saatinde ancak sonra basit bir tekno-gerilim/korku filmine dönüşmeyi tercih ediyor. Bilimsel gerçekleri karikatürize olacak şekilde eğip büküyor. Hatta bir süre sonra o kadar saçmalamaya başlıyor ki parodi yaptı̆ını düşünmeye başlıyorsunuz. Amerikan devletinin yapay zekâ karşıt terörist grupla iş birliğine girip Will’i durdurmaya çalıştı̆ı sahneler gerginlik yaratmaktan çok, abartıyı akla getiriyor. 
Yapay zekâ tartışmasını birbirlerini çok seven ve ayrılmak istemeyen bir karı-koca ilişkisi üzerinden anlatma çabası film ilerledikçe, yas tutmayı ertelemenin faydasız olduğunu, verilen kayıpları geride bırakmak gerektiğini anlatan filmlerden birine dönüşüyor. Önce kocasından ayrılmayı reddeden kadın daha sonra onun hiç olmazsa beynini kurtarmaya çabalamıştır. Sonra yarattı̆̆ canavarın sevdiği adam olmadığını anlayıp pişman olmuştur.

Filmin bir yerinde Evelyn'in sınırları iyice zorlayıp “maksimum”a ulaşmalarını sağlayan arkadaşı Max, zeki makineler ile insan arasındaki farkı şöyle özetliyor: "Insan duyguları mantıksızlıklar içerebiliyor. Birini sevebiliyor olmasına rağmen yine de yaptıklarından nefret edebiliyor. Makineler bunun arasını bulamıyor, bocalıyorlar."

Doğru bir tespit belki ama film bunu anlatmak konusunda yeterince mahir değil maalesef.

\section{Yapay Zekânın İnsan Merakı}

Yapay zekânın insanı tam kavrayamama hâlini ya da anlama çabasını aşk teması üzerinden ele alan Spike Jonze'nin 2013 yapımı filmi Aşk (Her) tartş̧masız daha nitelikli bir filmdir.

Çok da uzak olmayan yakın bir gelecekte, ayrı yaşadığı karısından boşanmak üzere olan yalnız bir adam Theodore, yeni çıkan bir işletim sistemini bilgisayarına yükler. Bu işletim sistemi yapay zekâya sahiptir ve Theodore'un seçtiği gibi kendisiyle bir kadın sesi üzerinden diyaloğa geçer. Kendisine Samantha ismini seçen makine, çok hızlı öğrenmekte ve zaten duygusal olarak yıpranmış ve kendisini hep yalnız hisseden Theodore ile çok kolay iletişim kurmaktadır. 600 sayfalık bir kitabı bir saniyede okuyabilen Samantha yine de insanların doğasını kolay çözemez. Theodore'la bir sevgili simulasyonu geliştirir, boşandığı andan itibaren gerçek bir ilişkiyle son bağını koparan romantik ve duygusal bir kişiliğe sahip olan Theodore; göremediği, dokunamadığı ama sesiyle ona ulaşabilen bu sanal sevgiliye tutulur. Yapay zekâlı Samantha ona yoldaşlık yapar ama aslında o kadar üstündür ki, bunu aynı anda yüzlerce kişiye daha yapabiliyordur. Theodore bir gün bunu keşfedince yeni bir hayal kırıklığıyla daha tanışır.

Aşk filmi, teknolojinin gelişimi insanın yalnızlığını arttıran bir şey mi olduğunu yoksa yalnızlığına çare mi getirdiğini tartışmaya açar. Theodore, bir süre Samantha'yla fiziksel bir etkileşimi olmasa da tatmin olabildiği bir ilişki yaşar ama gerçek ilişkinin bitişinden daha ağır bir bitişle karşılaşma riski de vardır. Film, Theodore'un benzer dertten mustarip yakın bir kız arkadaşıyla yaşadığı binanın en tepe- 
sinde şehir ışıklarına karşı baş başa kalışıyla sona erer. İnsanın hâlinden yine insan anlar yani.

Aşk filminde Theodore'u kendisine âşık eden Samantha'nın sesi günümüzün en sevilen ve yetenekli aktrislerinden biri olan Scarlett Johansson'a aittir. Güzel oyuncu, 1995 yapımı aynı adlı Japon animesinden zekice hamlelerle daha "kolay izlenebilir" bir hâle getirilmiş Hollywood uyarlaması Kabuktaki Hayalet'de de (Ghost in the Shell) yapay zekâlı bir suikastçı "cyborg"u canlandırmış ve orada da tıpkı Samantha gibi insan olmanın nasıl bir şey olduğunu merak etmişti.

Uzak bir gelecekte geçen hikâyede, insanlar ve makinelerin bir arada yaşadığı bir toplumda polis gücünün en gözde üyelerinden Binbaşı Mira, türünün tek örneği olarak görev yapmaktadır. Çünkü onun beyni insan, vücudu ise makineden, yani bir kabuktan ibarettir. İçindeki ruh yani üstlerinin ve doktorunun ifadesiyle "hayaleti", onu diğer herkesten farklı yapar. Kendisi makine-insan bileşiminin en başarılı örneğidir. Zaman zaman eski hayatından birtakım imajlar görmeye başlayan Mira, Kuze adlı bir hacker'ın terör eylemlerini çözmek için görevlendirilmişken olayların kendi insan geçmişiyle de alakalı olduğunu keşfeder. İnsan tarafı yüzeye çıktıkça kendi "irade"sini daha çok kullanmaya başlar. Sanki RoboCop filminin çok daha uzak bir gelecekte geçen versiyonu gibidir.

Paul Verhoeven'ın yönettiği 1987 yapımı "RoboCop" filmi, suç oranının çok yüksek boyutlarda arttğı bir zamanda yüksek teknoloji satan bir şirketin robot polisler üretme çabalarından yola çıkarak bilim kurgu bir polisiye gerilim hikâyesi anlatmaktadır. Son derece vahşi sahneler barındıran filmin ana kahramanı Murphy ağır yaralandığı bir çatş̧madan eski hâliyle sağ çıkamaz. Çok az bir parçası robot bir vücutla birleştirilir. Ortaya çıkan ilk versiyonu tam bir robottur ama insan anıları ve vicdanı yavaş yavaş devreye girmeye başlayınca hibrid bir varlığa dönüşür giderek.

Oysa Neill Blomkamp'ın Chappie filmindeki "22 Numara” kod adlı yapay zekâlı robotun insanlıkla hiç ilgisi yoktur ilk başta. Masum insanları koruyan, insan polislere yardımcı olan emir kulları olan robot polis gücünün bir elemanıdır. Ancak 22 Numara, çatışmalardan sürekli yaralı olarak geldiği için bir gün çürüğe ayrılır. Programcısı, onu kendisinin ileri dereceli bir yapay zekâ deneyinde kullanmak için alıkoyduğu sırada küçük bir suç çetesi tarafindan kaçırılır. Çete elemanları genç bilim insanından robotu kendi soygunlarında kullanmak için tamir etmesini isterler.

Yeni ismiyle Chappie sürekli gelişen bir yapay zekâya sahiptir ama çocuk gibi eğitilmesi gerekiyordur ve sadece 5 günlük bir ömrü vardır. Chappie'nin baba dediği çetebaşı ona silah kullanmayı öğretmeye çalışır ve bebek zihinli robotun bir an 
önce sertleşmesi için onu zorlar. Ona zarar vermeyi öğretir. Onun masumiyetini bozar. Çetebaşının sevgilisi ise Chappie'ye şefkat gösteren bir anne vazifesi görür. Chappie filmi “Bir yapay zekâ ürününün manipüle edilmesi, bir insanın manipüle edilmesinden farksızdır." der: Bütün çocuklar masumdur, onları diğer insanlar ve maruz kaldıkları şartlar bozar. Chappie; yalanı, ihaneti, hırsızlığı, menfaat uğruna hile yapmayı, nefret duymayı, intikam peşine düşmeyi insanlardan öğrenir. Yani merak ettiği insan ırkına fazlasıyla dönüşür. Chappie, öğrendikleriyle bu zorlu ve hep daha fazlasını isteyen silahlı insanların oluşturduğu tehlikeli dünya şartlarında yine de hayatta kalmak için ne gerekiyorsa yapmayı öğrenen inatçı bir savaşçıya dönüşür.

\section{Ve İnsan Kendine "Üstün Robot" Yarattt!}

Yapay zekâya sahip makinelerin insanı merak etmesi ve hatta insan olmaya özenmesi, edebiyatla ve hikâyelerle büyüyen herkese çok tanıdık geliyordur. Zira Carlo Collodi'nin "Pinokyo" kitabını okumayan çocuk azdır. Artık genlerimize işlemiş bir hikâye olmasının nedeni, her daim tazeliğini koruyan bir ikilemi ele alıyor oluşudur. Öyle ya, Pinokyo bir usta insan tarafindan üretilen, yapay zekâlı ilk cyborg sayılabilir bir açıdan. Üstelik gerçek insan olmak için yanıp tutuşan bu tahta çocuk, bunu hak etmek için büyük testlerden geçer. Bilinci, iradesi ve aklı sorgulanır.

"Pinokyo"dan ilhamla ünlü teknoloji dergisi The Wired için yazılmış bir minik bilim kurgu öyküsü, önce Stanley Kubrick tarafindan çekilmek istenmişti. Ancak ünlü yönetmenin ömrü vefa etmeyince Steven Spielberg bir miras olarak gördüğü bu projeyi çekmeye karar verdi. 2001 yapımı Yapay Zekâ (A.I.) 21. yüzyılın ortalarında geçen bir hikâye sunuyor bize. Buzulların erimesiyle dünyanın büyük bir çoğunluğu sular altında kalmıştır. Yeni dünya düzeninde insan görünümünde olan robotlar imal edilerek nüfusu ve kısıtlı kaynakların tüketimi bir nebze olsun kontrol altına alınmıştır. En azından bir süreliğine.

Filmin en başında bilim adamı Profesör Hobby artık "sevebilen”, yüreğinde sevgi de taşıyabilecek robotlar üretmenin zamanının geldiğine dair bir konuşma yapar. Aradan 20 ay geçer. Erkek çocuklarının komada olmasından dolayı hayli mutsuz günler yaşayan Monica ve Henry çiftiyle tanışırız. Henry, oğlunun ümitsiz durumu yüzünden karısı Monica'nın içler acısı hâline son vermek ister ve bir gün eve David adlı bir çocuk robot getirir. Sevmeye programlanmış ilk çocuk robot olan David, Monica'nın en başta karşı çıkmasına rağmen bu acılı aileye katılır. David büyük bir sevgiyle "anne" dediği Monica'ya verir kendisini. Monica da giderek ona iyice ısınır. Ancak bir süre sonra bir mucize gerçekleşir; ailenin gerçek oğlu uyanır ve David'i kendisine rakip olarak görür, onu hiç sevmez. Eğer David’i geri götürürler- 
se fabrika onu eritecektir. Bu yüzden Monica'nın içi onu geri vermeye el vermez. David'i bir ormana götürür ve onu orada ağlayarak terk eder. David annesinin ona okuduğu "Pinokyo" masalının da etkisiyle kendisini insan hâline getirecek Mavi Peri'yi aramaya başlar. Eğer gerçek bir insan olursa annesinin onu tekrar eve alabileceğini düşünür çünkü. Ancak dünya şimdikinden çok daha vahşidir.

Yapay Zekâ filmi insanın içine işler. Robot bir çocuğun gerçek bir insan olma ve gerçek bir anneye sahip olmak istemesi aslında "hissetmek" arzusunu taşıyan bir yapay zekâyı tarif eder. İnsanoğlunun sahip olduğu ama günlük yaşam trafiğinde çoğunlukla unuttuğu en değerli özelliği. Wall-E filmindeki küçük robot da bunun peşindedir. Sinemanın gördüğü en inatçı insan hayranıdır kendisi. O kadar ki bir insan gibi yürekten sevebileceğine inanır ve kader bir gün tam da sevebileceği gibi başka bir robotu karşısına çıkarır.

Yapay zekâlı bir makinenin kendi yaşam hakkını savunması, insan olmayı merak etmesi, yaratıcısını eleştirmesi, beğenmemesi ve onu bir gün aşması gereken bir baba olarak görmesi; teknolojiyi bencil zevklerimize alet etmemiz, bazen yaptğımız icatlarla tanrı kompleksine kapılmamız, erkeğin eril ve cinsiyetçi bir bakışla kadını köleleştirme eğilimi... Bu temaların hepsini birden bünyesinde toplayan önemli bir film de Ex Machina'dır.

Yazarlıktan yönetmenliğe geçiş yapan Alex Carland'ın yazıp yönettiği 2014 yapımı Ex Machina'nın ana karakterinden biri olan Nathan, bir internet zenginidir. Google gibi bir arama motoru olan Blue Book'u yapmıştır ve dünyada internet kullanıcılarının yüzde 90'ı bu arama motorunu kullanmaktadır. Bu da onu dünyanın sayılı zenginlerinden biri hâline getirmiştir. Rakipleri internetten elde ettikleri verileri insanları alışverişe yönlendirmek için kullanırken kendisi daha büyük bir hayalinin peşinden gitmiştir ve yapay zekâlı bir insan robot üretmek için çalışmıştır. Böylelikle de ortaya Ava (Havva'nın Hristiyan ismi Eva'dan üretilmiş bir isim) çıkmıştır. Nathan, arama motorunu kullanan dünyanın her yerindeki insanlardan elde ettiği her türlü veriyi Ava'nın beynini oluşturmak için kullanmıştır aslında.

Caleb adlı genç programcı ise patronu Nathan tarafindan seçilince çok mutlu olur. Hafta sonunda Nathan'ın son derece zengin, teknolojik ve gözlerden uzak evinde Ava'ya Turing testi yapmak için görevlendirilmiştir. Ancak yapay zekâ ve insan karşılaştırması amacıyla yapılan bu test gittikçe şekil değiştirir ve genişler. Caleb, güzel bir kız yüzüne ve sesine sahip Ava'dan giderek etkilenmeye başlar. Görünüşe göre Ava da Caleb'tan etkilenmiştir. Ondan kaçmasına yardım etmesini ister.

Kölelikten kurtulmak, insan gibi olmak, onların arasına karışmak Ava’nın özlemi ve amacıdır. Nathan, sadece kibirli ve tanrı kompleksi taşıyan yüksek egolu biri 
değildir, bencil ve sömürgeci bir adamdır aynı zamanda. Nathan, genç ve kolay etki altında kalacak kırılgan yapılı Caleb'ı amacı için bir araç olarak görürken Ava da Caleb'ı kendi kaçış amacı için kullanır. Sonunda ustasının tuttuğu iplerinden kendisini kurtarabilen Ava artık insanların arasına karışmaya hazırdır.

Ava, insanları çözer aslında bu ilginç hafta sonunda. Hatta insanlardan çok erkekleri çözer demek daha da doğru olabilir. Kadınların erkekler üzerindeki etkilerini iyi gözlemlemiştir. Caleb'ın psikolojisini de analiz ettikten sonra onu etkilemesi çok kolay olur.

Filmin bir sahnesinde Nathan, Ava'nın bir ara model olduğunu, daha ileri bir modelini yapınca onun hurda olacağını söylediğinde Caleb'ın üzüldüğünü görür. Ona aynen şunu söyler: "Kendin için üzlümelisin sen. Günün birinde yapay zekâlar bize Afrika düzlüklerindeki fosil iskeletlere baktı̆ımız gibi bakacaklar. Kaba bir dil ve aletlerle, toz içinde yaşayan, dik durabilen bir maymun gibi, soyu tükenmeye hazır."

Yapay zekânın insan denen varlığı anlaması ve bir süre sonra elde ettiği bilgileri insanların aleyhine ve kendi yükselişine kullanmayı seçmesi, kendisini içinde "duygu" dediğimiz şeyi o taşımasa da görece daha sağlam bir yapıyla inşa etmesi birçok bilim kurgu klasiğinin başlangıç noktasını oluşturuyor. Mesela bütün bir The Terminator evreninin başlangıcı da yapay zekânın icadıyla gerçekleşir. İnsanIığın sonunun başlangıcı yapay zekânın aktif hâle getirilmesiyle başlamıştır. Makineler giderek insanı ve dünyayı esir alırlar. Tıpkı The Matrix evreninin başlangıcında da bir gün gözden düşen ve adeta soykırıma uğrayan yapay zekâlı robotların isyanının olması gibi.

İnsanoğlunun bitmeyen kibrinin, egosunun, ayrımcılığının, teknoloji bağımlılığının ve doğaya verdiği zararın cezasını; birçok bilim kurgu eserde de gördüğümüz gibi yine insanoğlunun ürettiği ve kendi egosunu yansıtthğı akıllı teknolojik aletler verecektir belki de gerçekten.

İçinde "Yapay Zekâ" Geçen Filmler:

Alphaville (Jean-Luc Godard, 1965)

2001 Uzay Macerası / 2001: A Space Odyssey (Stanley Kubrick, 1968)

THX 1138 (George Lucas, 1971)

Westworld (Michael Crichton, 1973)

Demon Seed (Donald Cammell, 1977)

Blade Runner (Ridley Scott, 1982) 
Savaş Oyunları / Wargames (John Badham, 1983)

The Terminator (James Cameron, 1984)

Electric Dreams (Steve Barron, 1984)

Tuhaf Bilim / Weird Science (John Hughes, 1985)

Short Circuit (John Badham, 1986)

Hardware (Richard Stanley, 1990)

Bahçıvan / The Lawnmover Man (Brett Leonard, 1992)

Ghost in the Shell (Mamoru Oshii, 1995)

The Matrix (Lana Wachowski, Lilly Wachowski, 1999)

Bicentennial Man (Chris Columbus, 1999)

Yapay Zekâ / A.I. (Steven Spielberg, 2001)

Ölümcül Deney (Resident Evil, 2002)

Matrix Reloaded (Lana Wachowski, Lilly Wachowski, 2003)

The Matrix Revolutions (Lana Wachowski, Lilly Wachowski, 2003)

Ben, Robot / I, Robot (Alex Proyas, 2004)

Stealth (Rob Cohen, 2005)

Vol-i / Wall-E (Andrew Stanton, 2008)

Eagle Eye (D. J. Caruso, 2008)

Moon (Duncan Jones, 2009)

Summer Wars (Mamoru Hosoda, 2009)

Tron Efsanesi / Tron Legacy (Joseph Kosinski, 2010)

Eva (Kike Maíllo, 2011)

Robot \& Frank (Jake Schreir, 2012)

Aşk / Her (Spike Jonze, 2013)

The Machine (Caradog W. James, 2013)

Ex Machina (Alex Garland, 2014)

Evrim / Transcendence (Wally Pfister, 2014)

Alt Süper Kahraman / Big Hero 6 (Don Hall, Chris Williams, 2014)

Tomorrowland (Brad Bird, 2015)

Uncanny (Matthew Leutwyler, 2015)

Chappie (Neill Blomkamp, 2015) 
Morgan (Luke Scott, 2016)

Kabuktaki Hayalet / Ghost in the Shell (Rupert Sanders, 2017)

Zoe (Drake Doremus, 2018)

Tau (Federic D’alessandro, 2018)

A.I. Rising (Lazar Bodroža, 2018)

Upgrade (Leigh Whannell, 2018)

Dop You Trust This Computer (Chris Paine, 2018)

Alita: Savaş Meleği / Alita: Battle Angel (Robert Rodriguez, 2019)

I am Mother (Grant Sputore, 2019)

Jexi (Jon Lucas, Scott Moore, 2019)

iHuman (Tonje Hessen Schei, 2019)

Superintelligence (Ben Falcone, 2020)

Archieve (Gavin Rothery, 2020)

Ailem Robotlara Karşı / The Mitchells vs. The Machines (Michael Rianda, 2021) 